\title{
Experiment on Sedimentation Property of Water Waste in Water Treatment Plants of Zhongyin
}

\author{
Haipeng Li \\ Shandong Academy of Governance, Jinan, 250014, China
}

\begin{abstract}
Keywords: Water Treatment Plants Sludge; Sludge Components; Sedimentation Property
\end{abstract}
\begin{abstract}
The raw water property changes greatly during the whole year leading to different sludge components and sludge characters in different periods. The Results of experiment on thickening property of sludge in water treatment plants of zhong-yin indicate that solid content of water waste is much higher, the sludge sedimentation velocity is much slower, the compression point is more indistinct. When the solid concentration is up to the critical concentration, in order to enhance sedimentation property, need to adjust the sludge charge cycle of sedimentation tank and filter runs timely; the sludge sedimentation property is similar when the sludge component is diverse during both the usual period of raw water and the low temperature and low turbidity period, the critical concentration is $0.20 \%$; on the other hand, the sludge sedimentation property of the low temperature and high turbidity period is different to another two periods, and the critical concentration is $0.95 \%$.
\end{abstract}

\section{Introduction}

At present, most of China's water supply plant integrated sludge is basically untreated directly into the water, or directly discharged into the municipal drainage network. Directly discharged into the water body, will cause the sludge in the water sludge, raise the river bed, block the channel, the impact of floods, resulting in acceptance of water pollution; direct discharge into the municipal drainage network, increased sewage treatment plant water and solid load, affecting the performance of its structures. In addition, the State Environmental Protection Agency requirements from 2000 onwards, the new or under construction of large-scale water treatment plant sludge must be disposed of, after discharge and then discharge. Based on this, the sedimentation test of the integrated sludge in the diversion project is carried out to provide the basis for the treatment of the sludge.

\section{Water Quality of Raw Water in the Water Plant}

Analysis of Raw Water Quality. Longhu bubble reservoir existing water quality belongs to NaHCO3 type, the total stock of water amounted to 347 million cubic meters, the total salinity of about $600 \mathrm{mg} / \mathrm{L}, \mathrm{pH}$ higher, perennial $8.6 \sim 9.2$, is a secondary drinking water source. Raw water $\mathrm{pH}$ value is high, the alkalinity is high, the hardness is low, the aluminum content is high, the turbidity change big is its main characteristic. According to perennial observation, the average monthly turbidity distribution of raw water is shown in Fig 1. 


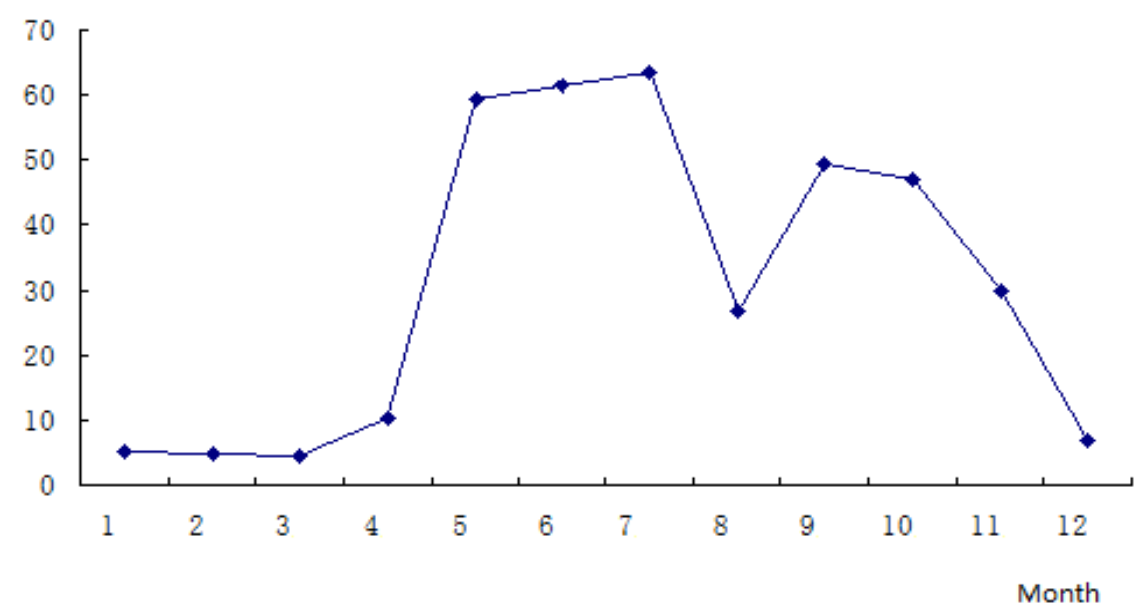

Figure 1 The annual average monthly turbidity curve in the water plant

Raw Water Quality Stage Division. Figure 1 and combined with the years in the water plant in the water quality of the observation and analysis can be drawn:

August to November, the water diversion water turbidity, the basic between $30 \sim 60 \mathrm{NTU}$, the basic color between 18 to 28 degrees, the $\mathrm{pH}$ value of 9.0 or so, the water temperature at $20 \sim$ $26{ }^{\circ} \mathrm{C}$, iron content of $0.4(\mathrm{CaCO} 3)$ is between 95 and $120 \mathrm{mg} / \mathrm{L}$, the basicity is about $175 \mathrm{mg} / \mathrm{L}$, and the sulfate content is between 9.0 and $10.0 \mathrm{mg} / \mathrm{L}$, Polymerization of aluminum chloride coagulant dosage of $17 \mathrm{mg} / \mathrm{L}$ or so.

December to April next year for the winter cold period, the water tank turbidity most of the time in $10 \mathrm{NTU}$ below the basic color between 10 to 20 degrees, $\mathrm{pH}$ value of 8.5 or so, the water temperature of 3 to $5{ }^{\circ} \mathrm{C}$, iron , The total content of manganese (CaCO3) is between 110 and 180 $\mathrm{mg} / \mathrm{L}$, the basicity is between 190 and $260 \mathrm{mg} / \mathrm{L}$, the content of sulfate is between 8.0 and 14.0 $\mathrm{mg} / \mathrm{L}$, and the turbidity is low , Polymerization of aluminum chloride coagulant dosage of 20mg / L or so.

From May to July, before and after the ice open, by the impact of wind turbulence, the water so that the bottom of the pool upside down, raw water turbidity rise in the low temperature season, sometimes up to 500NTU or more, usually between $50 \sim 70 \mathrm{NTU}$, The total hardness (CaCO3) is about $130 \mathrm{mg} / \mathrm{L}$, the alkalinity is about $200 \mathrm{mg} / \mathrm{L}$, and the sulfuric acid content is about 15 $25{ }^{\circ} \mathrm{C}$, the $\mathrm{pH}$ value is about 8.5 , the water temperature is $4 \sim 6{ }^{\circ} \mathrm{C}$, the content of iron and manganese is not excessive, Salt content of $10.0 \mathrm{mg} / \mathrm{L}$ or so. The dosage of polyaluminium chloride coagulant is about $15 \mathrm{mg} / \mathrm{L}$.

In order to facilitate the experimental study, according to the change of raw water temperature and turbidity, the raw water quality of the diversion plant can be divided into the original level ( 8 11 months), low temperature and low turbidity (12 4 months), low temperature and high turbidity 5 to 7 months) three stages.

\section{Test Content and Method}

Experimental Research Content. The sediment concentration test was carried out to determine the critical concentration of sludge sedimentation and the sediment sludge was tested.

The critical concentration of sludge sedimentation is defined as the decrease of the mud surface height of sludge from $1000 \mathrm{~mm}$ to $500 \mathrm{~mm}$ in $4 \mathrm{~h} \sim 5 \mathrm{~h}$, that is, the corresponding sludge concentration is $50 \%$.

Test Items and Equipment. Sludge composition percentage, sludge concentration, muddy water interface height

The main equipment is: the use of marked with diameter $250 \mathrm{~mm}$, height of $1 \mathrm{~m}$ plexiglass settling column and $1 \mathrm{~L}$ glass cylinder, GZX-DH-40 $\times 45$ electric thermostat oven, AB204-E-type electronic balance, ZRJ1- 6-type six-joint mixer, EYELA ELECTRIC FURNACE TMF-2200 
muffle furnace, DKQ-3C intelligent temperature control electric heater, CEM sealed microwave digestion equipment, two plastic high pressure tank and explosion-proof jacket, two $50 \mathrm{~mL}$ plastic fixed capacity Wait.

\section{Test Results and Analysis}

Analysis of Sludge Sedimentation Performance at Normal Level. The process of sedimentation of different concentrations of integrated sludge during this period is shown in Fig 2.

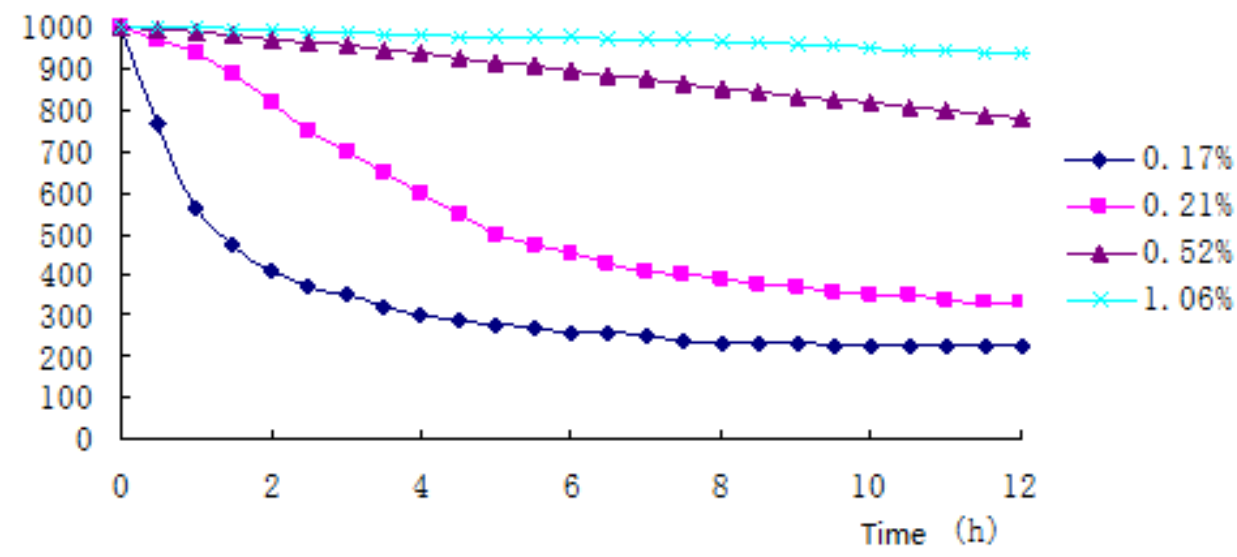

Figure 2 Different sedimentation curves with solid sludge

It can be seen from Figure 2 that the higher the concentration of sludge, the slower the change of mud surface height after settling, indicating that the slower the sedimentation rate and the less pressing point is. According to the critical concentration of sludge sedimentation, the critical concentration of sludge sedimentation is about $0.20 \%$. The sludge composition during this period was tested and the results are shown in Table 1.

Table 1 Analysis of chemical composition of sludge at the original level

\begin{tabular}{c|c|c|c|c|c|c|c|c}
\hline ingredient & Burning reduction & $\mathrm{SiO}_{2}$ & $\mathrm{Fe}_{2} \mathrm{O}_{3}$ & $\mathrm{Al}_{2} \mathrm{O}_{3}$ & $\mathrm{CaO}$ & $\mathrm{MgO}$ & $\mathrm{Na}_{2} \mathrm{O}$ & other \\
\hline content (\%) & 18.50 & 26.03 & 2.95 & 24.30 & 1.58 & 0.64 & 0.45 & 25.55 \\
\hline
\end{tabular}

It can be seen from Table 1, during this period of sludge with larger particles of aluminum and silicon salt, the two accounted for more than $50 \%$ of the total sludge, and some organic algae caused by sludge burning reduction Up to $18.5 \%$. Since the sludge concentration is relatively low during this period, the sludge discharge shows better sludge settling performance.

Analysis of Sludge Sedimentation Performance at Low Temperature and Low Turbidity Stage. The process of sedimentation of different concentrations of integrated sludge during this period is shown in Fig 3.

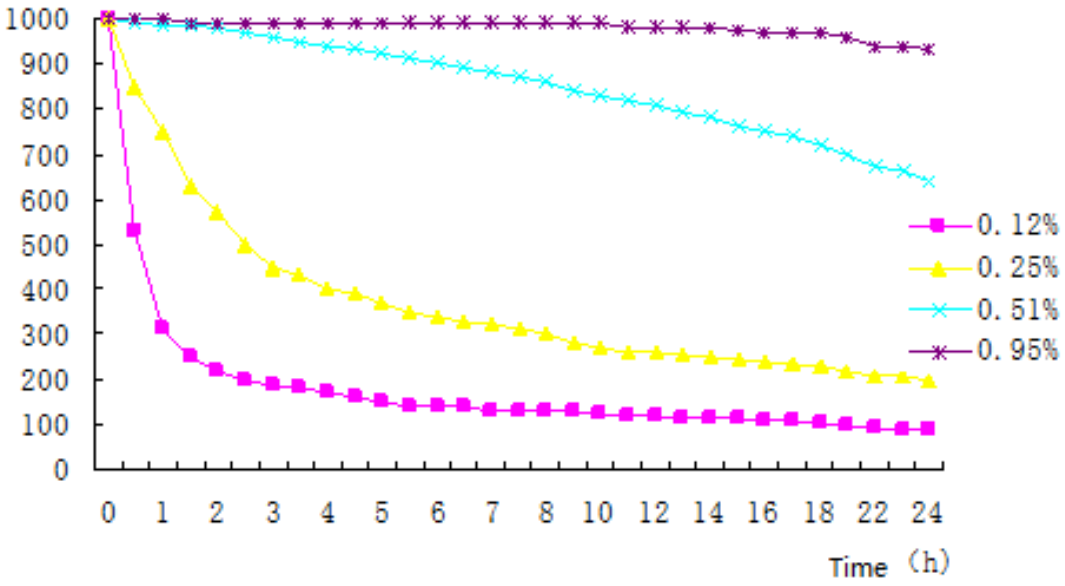

Fig.3 Low temperature and low turbidity period with different solid sludge settling curve 
It can be seen from Figure 3, low temperature and low turbidity period of muddy water settlement law and the original level of regularity similar to the critical sediment concentration of about $0.20 \%$. Due to the turbidity and temperature of the raw water, the sludge composition changes greatly, there are sludge with large coagulant content, but also sludge with inorganic grit and organic algae and coagulant content is relatively small. When the coagulant composition in the sludge is large, the separation of sludge and water is difficult and the sedimentation effect is very poor.

Analysis of Sludge Sedimentation Performance at Low Temperature and High Turbidity Stage. The sedimentation process of different concentrations of integrated sludge during this period is shown in Fig 4.

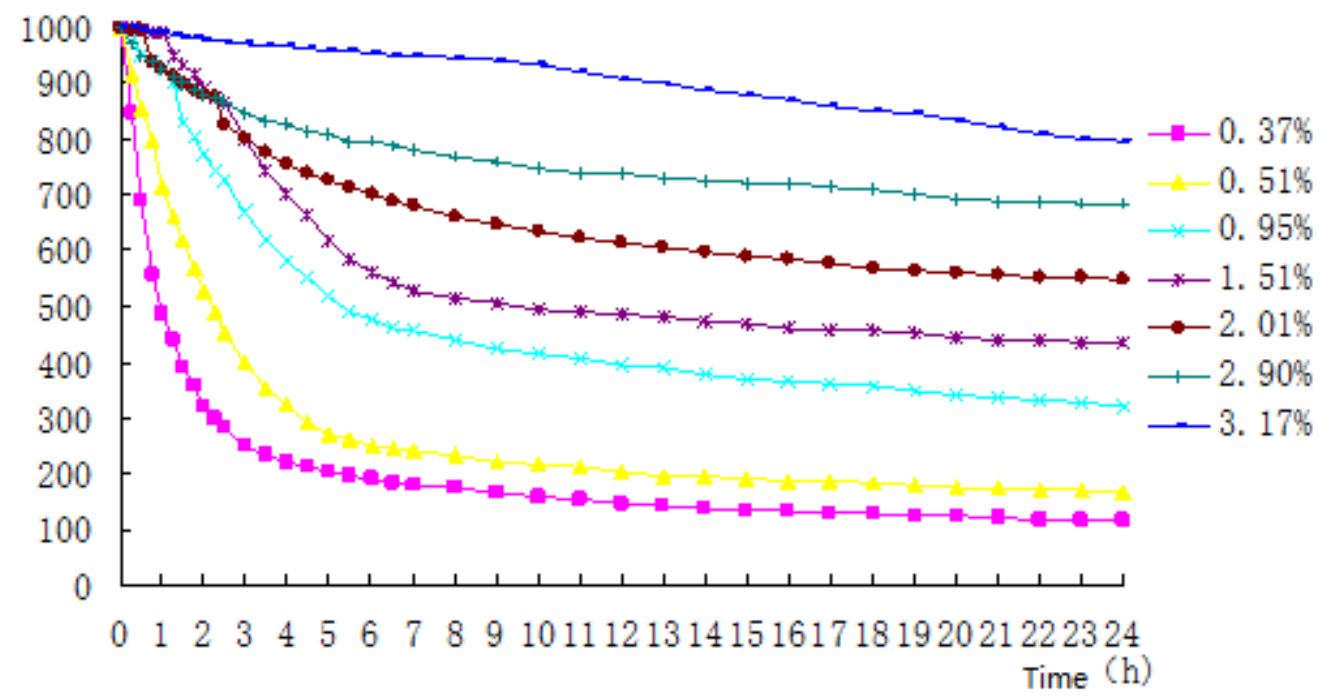

Fig.4 Settlement curves of solid sludge with low temperature and high turbidity

It can be seen from Fig. 4 that the critical concentration of sludge settling at low temperature and high turbidity is about $0.95 \%$. The results showed that the sludge concentration was larger than that of the other two periods due to the increase of the turbidity of the raw water, and the sludge in the sludge was mainly precipitated with alum in the alkaline earth particles and contained some organic algae.

Analysis of the Main Influencing Factors of Sedimentation Performance. The integrated water supply in the water supply plant belongs to the category of high turbidity water. At the same time, the annual water temperature is relatively low for the whole year. Combined with the test results, the factors affecting the settling performance of the sludge are analyzed from the following aspects.

The higher cohesive velocity is the necessary condition for the rapid generation of larger alum. The rate of agglomeration depends on the number of particle collisions per unit time and the effective collision rate, and the number of particle collisions is related to its velocity. When the water temperature is reduced, the thermal energy of the water molecules decreases, the rate of Brownian motion is naturally slowed down, and the chance of collision between particles is reduced, so the rate of agglomerating chemical reaction is slowed down.

The basic formula for particle collision is as follows:

$$
N=\frac{1}{6} n_{1} n_{2} \sqrt{\frac{p}{u}}\left(d_{1}+d_{2}\right)^{3}
$$

Where $\mathrm{N}$ - unit time, the number of particles per unit volume of collision;

$\mathrm{N} 1, \mathrm{n} 2$ - the number of particles in the unit volume of $\mathrm{d} 1, \mathrm{~d} 2$, respectively;

$\mathrm{P}$ - the power applied to the per cubic meter of water in the reactor;

$\mathrm{U}$ - absolute viscosity of water.

It can be seen from the above equation that when the turbidity is low, the number of particles in the water is reduced, so the number of collisions is less. When the water temperature is low, the 
impurity particles in the water are small and the number of particles collapsing decreases with the particle diameter.

The Stokes formula is:

$$
V=\frac{1}{18} \frac{\rho_{p}-\rho_{1}}{u} g d^{2}
$$

Where V-particle precipitation rate;

, - the density of particles and water;

U - absolute viscosity of water;

G-gravity acceleration

D-particle diameter.

When the relative movement of particles and water in the water is in the laminar flow, it can be concluded from the Stokes formula that the velocity of the particles in the water is proportional to the particle size and density, and is inversely proportional to the viscosity of the water. Moreover, from the sedimentation theory, the intercepting velocity $\mathrm{u}$ also plays a certain role, but when the settling velocity $\mathrm{V}$ of the particles is larger than the intercepting velocity $\mathrm{u}$, it settles in the sedimentation tank. When $\mathrm{V}$ is less than $\mathrm{u}$, the particles flow out of the pool. In the low temperature season, the sludge particles are mostly destabilized, poorly agglomerated particles with smaller particle size. The sedimentation rate is naturally smaller than the normal closing flow rate $\mathrm{u}$, which leads to the relatively low water temperature and turbidity settlement effect is not good.

The moving particles in the water have electric potential and charge. There are two forces between the two charged particles, one is the inherent gravity of the van der Waals force; the other is the electrostatic repulsion, the two kinds of rubber particles will change with the size of its spacing. At a certain temperature, the particles have a certain kinetic energy, if the kinetic energy is sufficient to overcome the approaching process in the emergence of the maximum repulsion, and can continue to close to a certain range, the sharp increase in the van der Waals force to attract, these particles can be aggregated into some slightly larger particles, otherwise the two particles will be separated again, still in the original state exists in the water. When the water temperature decreases, the kinetic energy of the colloidal particles decreases, so that it can hardly cross the repulsive energy peak. At the same time, when the turbidity of the sludge is low, the number of collisions of the colloidal particles is relatively reduced, so that the stabilization effect Mud settling performance.

If the ratio of $\mathrm{Al} 3+/ \mathrm{S}$ is larger, the most easily soluble product is formed. Since the space grid has no cross- , and thus easy to damage, resulting in poor sludge sedimentation performance.

\section{Conclusion and Suggestions}

(1) The difference of raw water quality caused the difference of sludge composition and traits, which became the main factor affecting the settling capacity of integrated drainage in the diversion project. In the middle level of the diversion plant, the original sludge component has the largest number of aluminum salts and silicon salts with large particle size and some organic algae. The low temperature and low turbidity sludge component is mainly coagulant, gravel and organic algae; low temperature and high turbidity of the sludge components to alkaline earth particles alum precipitation mainly, and contains some organic algae.

(2) the higher the sludge concentration, the slower the sludge settling speed, the more obvious the density point. And the critical concentration of sludge settling in the two stages of the original level and the low temperature and low turbidity stage are about $0.20 \%$. At high temperature and high turbidity, the sludge concentration is higher and the sludge concentration is higher than that in the first two stages.

(3) When the sludge concentration exceeds the critical concentration value, in order to improve the sedimentation efficiency of the sludge, you can adjust the water tank sedimentation tank drainage cycle and the filter backwash cycle to adjust the integrated sludge concentration to improve the settlement effect. 


\section{References}

[1] Fei Xiaoli, Cui Foyi. Experimental Study on Dehydration Performance of Sludge in Jiulong River Watershed of Fujian [J]. Water Supply and Drainage, 2004, 30 (4): 1 - 5

[2] ZHANG Fang-mei, CHEN Shao-wei, ZOU Wei-guo, et al. Study on enrichment performance of sediment sludge in water purification plant [J]. Water supply and drainage, 2000, 26 (7): 14 -17

[3] Chen Jing, Chen Shicai, Xu Jianhua et al. Experimental study on static and concentration of sludge in water plant [J]. China Water Supply and Drainage, 2005, 21 (2): 40-43

[4] Wang Pu, Long Tengrui, Li Jiangtao et al. Sludge Treatment and Energy Consumption in Urban Water Supply Plant [J] .Journal of Chongqing Jianzhu University, 2005,27 (4): 77-80

[5] Song Jianjun. Low sediment concentration seawater pumping station design points [J]. Water supply and drainage, 2004, 30 (8): 12-16 